\title{
Molecular Analysis of Major Histocompatibility Complex Alleles Associated with the Lupus Anticoagulant
}

\author{
Frank C. Arnett, Mary L. Olsen, Kent L. Anderson, and John D. Reveille \\ Division of Rheumatology and Clinical Immunogenetics, Department of Internal Medicine, \\ The University of Texas Medical School at Houston, Houston, Texas 77225
}

\begin{abstract}
Autoantibodies to phospholipids (APA) occur frequently in systemic lupus erythematosus (SLE) and other autoimmune disorders and predispose to intravascular thromboses. Major histocompatibility complex (MHC) class II alleles (HLA-DR and DQ) were determined by restriction fragment length polymorphisms (RFLP) in 20 patients with APA (lupus anticoagulant). HLA-DQw7 (DQB1 *0301), linked to HLA-DR5 and -DR4 haplotypes, occurred in $70 \%$ and was significantly increased compared to 139 race-matched normal controls $(P=0.002, P$ corrected $[\mathrm{pc}]=0.05$, odds ratio $[\mathrm{OR}]=5.1)$. Moreover, the frequency of HLA-DQw7 was significantly higher in SLE patients with APA as compared with patients without APA but with other autoantibodies, including anti-Ro and $L a(P$ $=0.0001, \mathrm{pc}=0.002, \mathrm{OR}=10.7)$, anti-Ro alone $(P=0.001$, $\mathrm{pc}=0.02, \mathrm{OR}=11.2)$, anti-dsDNA $(P=0.001, \mathrm{pc}=0.02, \mathrm{OR}$ $=7.1)$, and possibly anti-Sm $(P=0.04, \mathrm{pc}=\mathrm{NS}, \mathrm{OR}=6.8)$ and anti-nRNP (U1-RNP) $(P=0.01, \mathrm{pc}=\mathrm{NS}, \mathrm{OR}=7.8)$. The $\mathrm{DQB1} * 0301$ allele of $\mathrm{DQw} 7$ showed the strongest association, while the frequencies of the DQA1 $* 0301(45 \%)$ and DQA1 *0501 (50\%) alleles did not differ from the controls. Among the HLA-DQB1 *0301 (DQw7) negative patients, all possessed HLA-DQw8 (DQB1 *0302) and/or HLA-DQw6 (DQB1*0602 or DQB1*0603) alleles. The HLADQB1 * 0301 chain shares an identical seven amino acid sequence with DQB1 $* 0302, * 0602$, and $* 0603$ chains in the third hypervariable region of the HLA-DQ molecule. This candidate "epitope" may play a role in mediating an autoimmune response to APA. (J. Clin. Invest. 1991. 87:1490-1495.) Key words: antiphospholipid antibodies • HLA-class II alleles • restriction fragment length polymorphism - systemic lupus erythematosus $\bullet$ autoantibodies
\end{abstract}

\section{Introduction}

Autoantibodies to phospholipids (APA) ${ }^{1}$ occur frequently (34$44 \%$ ) in patients with systemic lupus erythematosus (SLE) and,

This work was presented in part at the American College of Rheumatology meetings, Seattle, WA, October 1990 (1990. Arthritis Rheum. 33:S100 [Abstr.]).

Address reprint requests to Frank C. Arnett, M.D., University of Texas Medical School, P.O. Box 20708, Houston, TX 77225.

Received for publication 12 October 1990 and in revised form 11 December 1990

1. Abbreviations used in this paper: APA, autoantibody to phospholipids; BFP, biologic false-positive; dsDNA, double-stranded DNA; MHC, major histocompatibility complex; RFLP, restriction fragment length polymorphism; SLE, systemic lupus erythematosus.

J. Clin. Invest.

(c) The American Society for Clinical Investigation, Inc. 0021-9738/91/05/1490/06 \$2.00

Volume 87, May 1991, 1490-1495 less often, in those with other connective tissue diseases (reviewed in reference 1). Although recognized for many years as the cause for a biologic false-positive (BFP) test for syphilis and a circulating lupus anticoagulant $(2,3)$, and, more recently, by anticardiolipin assays (4), their clinical relevance to disease manifestations is only now being appreciated. Recent studies indicate strong correlations of APA with intravascular thromboses, recurrent spontaneous abortions, Libman-Sack's endocarditis, and livido reticularis $(1,5)$. Moreover, a causative role for these antibodies in these disease complications seems likely. A "primary antiphospholipid syndrome" has even been proposed based on patients presenting with these clinical features in association with anticardiolipin antibodies or a lupus anticoagulant who do not fulfill criteria for SLE or other connective tissue disease $(5,6)$. In fact, APA have been detected in $3-4 \%$ of patients presenting with strokes $(7,8)$, and we have found recently a $9 \%$ prevalence of the lupus anticoagulant in 100 consecutive patients admitted to a neurology service.

SLE is a clinically and serologically heterogeneous disease in which genetic factors appear to play important roles. HLADR2 and HLA-DR3 each show weak associations with SLE (9, 10); however, stronger HLA class II correlations have been found for several autoantibodies expressed in SLE patients (11-13). Such findings suggest that these autoimmune responses, some of which may play direct pathogenetic roles, are genetically mediated by antigen-specific $\mathrm{T}$ helper lymphocytes (14).

The purpose of this study was to determine whether any HLA-DR and/or -DQ alleles were associated with antiphospholipid antibodies as defined by the presence of a circulating lupus anticoagulant. Moreover, immunogenetic differences were sought between connective tissue disease patients expressing the lupus anticoagulant and those, especially with SLE, having other autoantibody profiles. HLA-DR and -DQ alleles were defined at the DNA level using restriction fragment length polymorphisms (RFLP), so as to more precisely define the specific alleles and potential nucleotide (and their inferred amino acid) sequences associated with this autoimmune response.

\section{Methods}

Patients and controls. As an ongoing study, all patients with connective tissue diseases followed by the Division of Rheumatology and Clinical Immunogenetics are studied routinely for a variety of autoantibodies and undergo HLA-DR and -DQ typing by RFLP after informed consent is obtained. 20 such patients ( 16 white and 4 black) with a circulating lupus anticoagulant have been identified and constitute the basis of this study. For purposes of immunogenetic comparison, patients with other autoantibody profiles but who were negative for the lupus anticoagulant were selected. These included (a) 24 patients ( 5 white and 19 black) with SLE who possessed anti-Sm with or without anti-nRNP (U1-RNP), (b) 26 patients (13 white and 13 black) with SLE who were positive for anti-nRNP (U1-RNP) without anti-Sm, (c) 45 patients (23 white and 22 black) with SLE or Sjogren's syndrome who were positive 
for anti-Ro (SS-A) but not anti-La (SS-B) (d) 57 patients ( 32 white and 25 black) with SLE or Sjogren's syndrome who were positive for antiRo and anti-La, and (e) 53 patients with SLE positive for high-titer anti-dsDNA antibodies. Because we were studying autoantibody subsets, it should be noted that patients with multiple autoantibodies could be represented in more than one of the above groups.

Normal controls included 79 local Caucasian and 60 local black volunteers who were blood donors or medical school personnel whose HLA-DR and -DQ alleles were similarly defined by RFLP analyses.

Autoantibody determinations. The lupus anticoagulant was defined by the tissue thromboplastin inhibition test (Sigma Chemical Co., St. Louis, MO) performed on freshly drawn citrated blood in the clinical laboratory. In addition, 16 of the 20 lupus anticoagulant positive patients had a prolonged activated partial thromboplastin time which did not correct with a 1:1 mix with fresh normal human plasma.

Antibodies to Sm, nRNP (U1-RNP), and La were detected by countercurrent immunoelectrophoresis against calf thymus and antiRo against human spleen extracts using our modifications (15) of the method of Johnson et al. (16). Antibodies to double-stranded DNA (dsDNA) were determined by indirect immunofluorescence using Crithidia luciliae as antigen substrate (17) and by ELISA using calf thymus DNA (Sigma Chemical Co.). Only those with titers $\geq 1 / 160$ on Crithidia luciliae and high levels of binding in ELISA were included in the anti-dsDNA positive group.

RFLP analysis of HLA-DR and DQ alleles. Genomic DNA was extracted from peripheral blood leukocytes (18) and $10 \mu \mathrm{g}$ digested with the restriction endonucleases Bam $\mathrm{HI}$ and Taq I under conditions specified by the manufacturer, and then electrophoresed through $0.8 \%$ agarose gel overnight at $50 \mathrm{~V}$. The gel was then stained in ethidium bromide, photographed, and subjected to denaturation and neutralization as described previously (19), and transferred onto Zetabind membranes (Cuno Inc., Meriden, CT).

Probes used in this study included a 770 bp Sac I/Hind III-cut full-length DRB1 cDNA (20), a 700-bp full-length Pst I-cut DQBI cDNA (21), and a 2.4-kb genomic Pst I-cut DQAI probe (22), which were radiolabeled with $\alpha \mathrm{CTP}^{32}$ by oligolabeling (23). Prehybridization and hybridization conditions were carried out as previously described (19).

HLA-DR and -DQ specificities were assigned to specific RFLP bands at the 10th International Histocompatibility Testing Workshop (24), as well as in our own $(25,26)$ and others' studies $(27-32)$. Specific DQA1 and DQB1 chain alleles in each individual were assigned by comparison with reported DQA1 and DQB1 RFLP's for specific HLA$D$ haplotypes as determined by the World Health Organization Nomenclature Committee for factors of the HLA system which met during the 7th International Congress of Immunology in 1989 (33).

Statistical analyses. Comparisons of HLA phenotype frequencies in lupus anticoagulant positive patients versus normal race-matched controls and other autoantibody subsets were performed using MantelHaenszel chi-square analysis which combined the $2 \times 2$ tables for each race using the EPISTAT statistical program. $P$ values were corrected for the number of HLA specificities examined. Relative risks were calculated as odds ratios, also using the Mantel-Haenszel method. Therefore, the odds ratios reported represent an averaged risk for combined white and black patients as compared to their respective combined race-matched controls.

\section{Results}

Among the 20 patients with a lupus anticoagulant, nine fulfilled the American College of Rheumatology criteria for SLE (34), eight were considered clinically to have a primary antiphospholipid syndrome (5), two had primary Sjogren's syndrome, and one had scleroderma. 15 had had clinically significant complications of the lupus anticoagulant including thrombotic cerebrovascular accidents (five patients), other central nervous system events (five patients), deep venous thromboses (four patients), or recurrent spontaneous abortions (three patients). Coexisting autoantibodies included anti-dsDNA in two with SLE, anti-Ro in three (two with Sjogren's syndrome and one SLE), anti-La in one (with Sjogren's syndrome), and anticentromere in one (with scleroderma).

Lupus anticoagulant versus normal controls. HLA-DR5, DRw52b (Dw25), and DQw7 were each significantly increased in patients with the lupus anticoagulant as compared with racematched normal controls (Table I). These three specificities were typically inherited as a haplotype in nine patients; the one additional DRw52b occurred on a DRw6 (13) haplotype, and the five additional DQw7 specificities were linked to HLADR4 haplotypes. All four of the black patients were positive for HLA-DR4, DQw7 haplotypes. Among the 10 HLA-DR4 positive normal black controls, only three $(30 \%)$ were linked to DQw7 and the remainder (70\%) to DQw8 $(P=0.07$, Fisher's exact test, two-tailed, for comparison of DQw7 linkage to DR4 in black patients versus black controls). Thus, in both whites and blacks HLA-DQw7 was the most common of these associated specificities $(70 \%)$ and was the only one which maintained statistical significance after correction for multiple comparisons (Table I). Among the six HLA-DQw7-negative patients, one was an HLA-DR4, -DQw8 homozygote, and the remaining five were HLA-DQw6 heterozygotes, including two with HLA-DQw8 and one with -DQw9 on the alternative haplotype. Thus, all patients with the lupus anticoagulant were positive for HLA-DQw7, -DQw8 or -DQw6.

Lupus anticoagulant positives versus other autoantibody subgroups. HLA-DR5, -DRw52b (Dw25), and -DQw7 were all increased in patients with a lupus anticoagulant compared to those with anti-Sm (with or without accompanying anti-U1RNP), anti-U1-RNP without anti-Sm, anti-Ro without anti$\mathrm{La}$, anti-Ro and -La, and anti-dsDNA antibodies (Table II).

A significant association of HLA-DQw7 was maintained in lupus anticoagulant positives as compared to anti-Ro, anti-La, and anti-dsDNA positives after correction of $P$ values for multiple comparisons, whereas HLA-DR5 and -DRw52b lost significance (except for DR5 and anti-Ro and -La). Moreover, HLADQw7 conferred the highest odds ratios for the lupus anticoagulant versus each of the other autoantibody subgroups.

$H L A-D Q A 1$ and $-D Q B 1$ alleles in patients with the lupus anticoagulant. HLA-DQA 1 and -DQB1 chain alleles comprising the DQw7 specificity were then determined from the RFLP patterns (32) (Table III). All of the DQw7-positives possessed the $\mathrm{DQB} 1 * 0301$ allele (as expected $)(P=0.002 ; \mathrm{pc}=0.05$; OR $=5.7)$. The DQA1 alleles, DQA $1 * 0301(45 \%)$ and DQA $1 * 0501(50 \%)$, were each represented in patients with APA, and their individual frequencies did not differ significantly from race-matched normal controls (Table III) or patients with other autoantibodies (data not shown). Among the DQw7-negative patients, the DQw8-positive patient was homozygous for DQA $1 * 0301$, DQB $1 * 0302$, and the DQw6positive patients had the DQA $1 * 0102$, DQA $1 * 0103$, $\mathrm{DQB} 1 * 0602$, and $\mathrm{DQB} 1 * 0603$ alleles each represented.

\section{Discussion}

Major histocompatibility complex (MHC) or HLA-class II alleles appear to play important roles in certain autoimmune responses. With recent applications of molecular genetic technology, specific MHC-encoded sequences, often shared by several HLA alleles in their polymorphic domains, have been as- 
Table I. HLA-DR and -DQ Antigen Frequencies Determined by RFLP in Patients with the Lupus Anticoagulant (LA) and in Normal Race-Matched Controls

\begin{tabular}{|c|c|c|c|c|c|c|c|}
\hline HLA & LAt & $n=20$ & $\begin{array}{c}\text { White } \\
\text { controls } \\
n=79\end{array}$ & $\begin{array}{c}\text { Black } \\
\text { controls } \\
n=60\end{array}$ & $P^{*}$ & $\mathrm{pc}^{*}$ & $\mathrm{OR}^{\mathbf{s}}$ \\
\hline & & $\%$ & $\%$ & $\%$ & & & \\
\hline DR1 & 0 & 0 & 27 & 20 & - & - & - \\
\hline DR2 $(15,16)$ & 5 & 25 & 27 & 23 & - & - & - \\
\hline DR3 (17) & 2 & 10 & 20 & 13 & - & - & - \\
\hline DR4 & 9 & 45 & 29 & 17 & 0.34 & - & 1.9 \\
\hline DR5 (11) & 9 . & 45 & 13 & 30 & 0.008 & NS & 4.2 \\
\hline DRw6 (13) & 3 & 15 & 28 & 18 & - & - & - \\
\hline DRw6 (14) & 1 & 5 & 10 & 18 & - & - & - \\
\hline DR7 & 5 & 25 & 19 & 25 & - & - & - \\
\hline DR8 & 3 & 15 & 6 & 8 & - & - & - \\
\hline DR9 & 0 & - & 5 & 0 & - & - & - \\
\hline DRw10 & 0 & - & 0 & 7 & - & - & - \\
\hline DRw52a (Dw24) & 4 & 20 & 39 & 42 & - & - & - \\
\hline DRw52b (Dw25) & 10 & 50 & 19 & 47 & 0.004 & 0.09 & 4.2 \\
\hline DRw52c (Dw26) & 2 & 10 & 10 & 10 & - & - & - \\
\hline DRw53 & 14 & 70 & 48 & 35 & 0.07 & NS & 2.8 \\
\hline DQw2.1 & 2 & 10 & 20 & 13 & - & - & - \\
\hline DQw2.2 & 4 & 20 & 15 & 27 & - & - & - \\
\hline DQw4 & 2 & 10 & 5 & 17 & - & - & - \\
\hline DQw5 & 3 & 15 & 33 & 33 & - & - & - \\
\hline DQw6 & 9 & 44 & 52 & 50 & - & - & - \\
\hline DQw7 & 14 & 70 & 32 & 35 & 0.002 & 0.05 & 5.1 \\
\hline DQw8 & 4 & 20 & 18 & 12 & - & - & - \\
\hline DQw9 & 1 & 5 & 8 & 2 & - & - & - \\
\hline
\end{tabular}

* Mantel-Haenszel analysis combining white and black patients and controls.

${ }^{\ddagger} P$ value corrected for 23 allelic comparisons.

Odds ratio.

Table II. Frequencies of Selected HLA Specificities Determined by RFLP in Autoantibody Subsets of Connective Tissue Diseases

\begin{tabular}{|c|c|c|c|c|c|}
\hline Autoantibodies & HLA & No.' (\%) & $P^{*}$ & $\mathbf{p c}^{\mathbf{t}}$ & $\mathrm{OR}^{6}$ \\
\hline Lupus anticoagulant (LA) & DR5 & $9(45)$ & - & - & - \\
\hline \multirow[t]{2}{*}{$n=20$} & DRw52b & $10(50)$ & - & - & - \\
\hline & DQw7 & $14(70)$ & - & - & - \\
\hline Anti-Sm \pm anti-U1-RNP & DR5 & $6(25)$ & NS & NS & 5.4 \\
\hline \multirow[t]{2}{*}{$n=24$} & DRw52b & $10(42)$ & NS & NS & 2.0 \\
\hline & DQw7 & $7(29)$ & 0.04 & NS & 6.8 \\
\hline Anti-U1-RNP without anti-Sm & DR5 & $6(23)$ & 0.10 & NS & 4.3 \\
\hline \multirow[t]{2}{*}{$n=26$} & DRw52b & $10(38)$ & NS & NS & 2.7 \\
\hline & DQw7 & $10(38)$ & 0.01 & NS & 7.8 \\
\hline Anti-Ro without anti-La & DR5 & $11(24)$ & 0.07 & NS & 3.7 \\
\hline \multirow[t]{2}{*}{$n=45$} & DRw52b & $18(39)$ & 0.34 & NS & 2.1 \\
\hline & DQw7 & $13(28)$ & 0.001 & 0.02 & 11.2 \\
\hline Anti-Ro and anti-La & DR5 & $7(12)$ & 0.02 & 0.02 & 8.2 \\
\hline \multirow[t]{2}{*}{$n=58$} & DRw52b & $14(24)$ & 0.01 & NS & 4.7 \\
\hline & DQw7 & $12(21)$ & 0.0001 & 0.002 & 10.7 \\
\hline Anti-dsDNA & DR5 & $8(15)$ & 0.01 & NS & 5.7 \\
\hline \multirow[t]{2}{*}{$n=53$} & DRw52b & $14(26)$ & 0.08 & NS & 3.0 \\
\hline & $\mathrm{DQw} 7$ & $15(28)$ & 0.001 & 0.02 & 7.1 \\
\hline
\end{tabular}

* Mantel-Haenszel analysis combining white and black patients in each group compared to those with the LA.

$\$ P$ value corrected for 23 allelic comparisons.

Odds ratio (Mantel-Haenszel).

1492 F. C. Arnett, M. L. Olsen, K. L. Anderson, and J. D. Reveille 
Table III. HLA-DQ Alleles in Patients with the Lupus Anticoagulant (LA) and in Normal Race-Matched Controls

\begin{tabular}{|c|c|c|c|c|c|c|}
\hline HLA & LAt & $n=20$ & $\begin{array}{c}\text { White } \\
\text { controls } \\
n=79\end{array}$ & $\begin{array}{c}\text { Black } \\
\text { controls } \\
n=60\end{array}$ & $P$ & OR \\
\hline & & $\%$ & $\%$ & $\%$ & & \\
\hline $\mathrm{DQB} 1 * 0301$ & 14 & 70 & 32 & 35 & 0.009 & 4.1 \\
\hline $\mathrm{DQA} 1 * 0301$ & 9 & 45 & 34 & 17 & NS & - \\
\hline DQA $1 * 0501$ & 10 & 50 & 37 & 40 & NS & - \\
\hline
\end{tabular}

sociated with predisposition to certain autoimmune diseases, such as insulin-dependent diabetes mellitus, rheumatoid arthritis, and pemphigus vulgaris $(14,35)$. Whereas these latter disorders are characterized by a limited number of autoimmune responses and usually single organ damage, patients with connective tissue diseases, especially SLE, may have one or more autoantibody systems. Moreover, certain clinical manifestations of these diseases are associated with the presence of certain circulating autoantibodies. Even before molecular genetic studies, HLA antigen associations in these disorders appeared to be more strongly correlated with certain autoantibodies than with the parent diseases $(11-15,36)$. With the use of RFLP, oligonucleotide probes, and nucleotide sequencing of MHC genes in autoantibody subsets of patients, it appears that a variety of polymorphic MHC class II sequences are associated with these autoimmune responses. For example, the anti-Jo-1 (histidyl tRNA synthetase) autoantibody associated with interstitial lung disease in polymyositis (but not anti-Jo-1 negative polymyositis) is associated with HLA-DRB1 first hypervariable region sequences shared by HLA-DR3, DR5, DRw6, and DRw8 (37). The anticentromere antibody in scleroderma is strongly correlated with an HLA-DRB1 third diversity region sequence shared by HLA-DR1 and DR4 (Dw13 and Dw14) (38). For SLE and Sjogren's syndrome, we have reported recently that the Ro (SS-A) and La (SS-B) autoantibodies are associated most strongly with HLA-DQA 1 alleles possessing glutamine in position 34 and HLA-DQB1 alleles having leucine in position 26 of their second hypervariable regions (39). For the anti-Sm and anti-nRNP (U1-RNP) responses, HLA-DQB1 codon (amino acid) position 57 appears to be critical (40). AntidsDNA antibodies are associated with the HLA-DRB $1 * 0201$, DRB $1 * 0602$, and DQB $1 * 0302$ alleles, each of which bears a methionine in position 14 and a leucine in position $26(41)$.
This study used a similar molecular approach to determine whether any HLA-DR or -DQ alleles were associated with antiphospholipid antibodies, as defined by a circulating lupus anticoagulant. Indeed, HLA-DR5, -DRw52b (Dw25), and-DQw7, which occur in linkage disequilibrium as a haplotype, were each increased in patients with the lupus anticoagulant as compared to race-matched normal controls. Of these alleles, HLADQw7 was most commonly present $(70 \%)$ and occurred on HLA-DR5 and/or HLA-DR4 haplotypes. Moreover, HLADQw7 was significantly increased in lupus anticoagulant positive patients when compared to those with anti-Ro, anti-La, anti-dsDNA, and possibly anti-Sm ( \pm anti-U1-RNP) and antiU1-RNP alone, whereas HLA-DR5 and DRw52b tended to lose significance when $P$ values were corrected for multiple comparisons.

There are two previous studies of HLA antigen frequencies, detected serologically, in patients with APA. Savi et al. (42) reported an increase of HLA-DR7 in Italian patients and McHugh and Maddison (43) an excess of HLA-DR4 in United Kingdom patients with SLE and anticardiolipin antibodies. In neither report were HLA-DQ frequencies described. In our study, all of the patients with HLA-DQw7 were HLA-DR4 or -DR5 positive. It may be notable that HLA-DR4 is in linkage disequilibrium with HLA-DQw7, whereas HLA-DR7 is not. HLA-DRw53 is linked to both -DR4 and -DR7; however, this allele was not significantly increased in our patients. Therefore, it appears likely that HLA-DQw7 is the most relevant allele; however, we cannot exclude the possibility of an effect(s) from HLA-DR5 and/or HLA-DRw52b (Dw25). Moreover, our study population was small and these results must be viewed as preliminary.

Because HLA-DQ molecules are comprised of polymorphic DQ $\alpha$ and $\mathrm{DQ} \beta$ chains, we then ascertained specific DQA 1

Table IV. Outer Domain Third Hypervariable Region Amino Acid Sequences Shared by Certain HLA-DQBI Alleles

\begin{tabular}{|c|c|c|c|c|c|c|c|}
\hline \multirow[b]{2}{*}{ HLA } & \multicolumn{7}{|c|}{ Amino acid positions } \\
\hline & 71 & 72 & 73 & 74 & 75 & 76 & 77 \\
\hline \multicolumn{8}{|c|}{ DQw7(DQB1 *0301), DQw8(DQB 1 *0302), DQw9(DQB1 *0303), } \\
\hline DQw6(DQB1 *0602, 0601, 0603, 0604) & $\underline{\mathbf{T}}$ & $\mathbf{R}$ & A & $\underline{\mathrm{E}}$ & $\underline{L}$ & D & $\underline{T}$ \\
\hline $\mathrm{DQw} 2(\mathrm{DQB} 1 * 0201)$ & $\underline{\bar{K}}$ & $\mathbf{R}$ & A & $\underline{A}$ & $\underline{\mathbf{V}}$ & $\mathbf{D}$ & $\underline{\mathbf{R}}$ \\
\hline $\mathrm{DQw5}(\mathrm{DQB} 1 * 0501 *, 0502,0503)$ & $\underline{\mathbf{A}}$ & $\mathbf{R}$ & A & $\underline{S}$ & $\mathrm{~V}$ & D & $\underline{\mathbf{R}}$ \\
\hline DQw4(DQB $1 * 0401,0402)$ & $\underline{\mathrm{D}}$ & $\mathbf{R}$ & A & $\underline{S}$ & $\mathbf{V}$ & D & $\underline{T}$ \\
\hline
\end{tabular}

From references $14,29,33$. Polymorphic residues are underlined. 
and DQB1 alleles from RFLP patterns as defined by the 7th International Congress of Immunology in 1989 (33). All of the HLA-DQw7 positives with the lupus anticoagulant possessed the DQB1*0301 allele which defines DQw7. HLADQA 1 *0301, which may occur on DR4, DQw7; DR4, DQw8; or DR9, DQw9 haplotypes was found in nine $(45 \%)$ of the patients and was not significantly increased when compared with normal control frequencies. Similarly, HLADQA 1*0501 which may occur on HLA-DR5 (DRw11 and DRw12), DQw7; DR3 (DRw17), DQw2; DRw6 (DRw14), DQw7; and DR2, DQw7 haplotypes occurred in $50 \%$ of the patients but was not significantly increased. Thus, HLA$\mathrm{DQB} 1 * 0301$ appears to show the strongest association with the autoimmune response producing the lupus anticoagulant.

The HLA-DQ specificities found in the HLA-DQw7-negative patients with the lupus anticoagulant may provide clues to the region of the HLA-DQ molecule involved in this autoimmune response. Interestingly, one patient was homozygous for HLA-DQw8 and the remainder were heterozygous for HLADQw6. Three of these latter patients were also heterozygous for HLA-DQw8 or -DQw9. It seems unlikely that the HLA-DQA1 alleles of -DQw7, -DQw6, and -DQw8 are primarily involved, because their amino acid sequences are quite different $(32,33)$. On the other hand, the HLA-DQB1 alleles of -DQw7 (DQB1*0301), -DQw6 (DQB1*0602, *0601,*0603 and *0604), -DQw8 (DQB1*0302) as well as -DQw9 (DQB1 *0303), share a common amino acid sequence (positions 7177 ) in the third hypervariable region of the outermost domain $(14,29,33)$ (Table IV). This DQB1 sequence, TRAELDT, is distinct from those found in the DQB1 alleles of HLA-DQw2, -DQw4, and -DQw5 and, as such, may represent an autoantibody predisposing "epitope". Based upon the hypothetical model for MHC class II three-dimensional structure proposed by Brown et al. (44), this sequence should map to the $\mathrm{DQ} \beta$ alpha helical region where it would be in a position to potentially bind the $\mathrm{T}$ cell antigen receptor. It will not be certain, however, where this sequence maps until the structures of class II molecules are definitively known. Moreover, in other diseases, such as rheumatoid arthritis and insulin-dependent diabetes mellitus, where particular amino acid sequences are implicated in disease, the alleles sharing these sequences are independently associated with the diseases $(14,37)$. It should be emphasized that, thus far, this is not the case for the lupus anticoagulant. HLA-DQw7 occurred more commonly in this population of patients with this antibody than did -DQw8 or -DQw6, despite the sharing of the same candidate -DQB1 sequences. Thus, there may be other relevant sequences and/or conformational determinants in the DQw7 molecule which more strongly promote this abnormal immune response. We did not find any HLA-DQ specificities that appeared "protective" (two patients had -DQw4, three -DQw5, and six -DQw2). Additional studies will be needed to determine whether this third hypervariable region sequence is the "epitope" which preferentially binds the currently unknown antigen responsible for the immune response resulting in a lupus anticoagulant.

It should be emphasized that we did not measure APA by cardiolipin assays but rather by the presence of a lupus anticoagulant. Therefore, additional studies will be necessary to determine whether the association of HLA-DQw7 with the lupus anticoagulant can be generalized to APA when measured as anticardiolipin antibodies. Nonetheless, these data suggest that patients with the lupus anticoagulant constitute an immuno- genetically distinct subgroup of SLE. Whereas autoantibodies to Ro, La, Sm, and dsDNA are associated with HLA-DQ alleles most often in linkage disequilibrium with HLA-DR3, DR2, and DRw6 haplotypes, the lupus anticoagulant occurs more typically with HLA-DQ alleles represented on HLA-DR5 and -DR4 haplotypes. Additional studies should be performed in other centers and in other ethnic groups to determine fully the MHC class II determinants of autoantibodies to phospholipids.

\section{Acknowledgments}

The authors wish to thank Mrs. Margaret Dougherty for preparation of the manuscript.

Supported by National Institutes of Health grant AR 39325, an Arthritis Foundation Clinical Research Center Grant, and a grant from the Texas Gulf Coast Chapter of the Arthritis Foundation. Dr. Reveille is an Investigator of the Arthritis Foundation.

\section{References}

1. Love, P. E., and S. A. Santoro. 1990. Antiphospholipid antibodies: anticardiolipin and the lupus anticoagulant in systemic lupus erythematosus (SLE) and in non-SLE disorders. Prevalence and clinical significance. Ann. Intern. Med. 112:682-698.

2. Conley, C. L., and C. Hartman. 1953. A haemorrhagic disorder caused by circulating anticoagulants in patients with disseminated lupus erythematosus. $J$. Clin. Invest. 31:621-623.

3. Feinstein, D. I., and S. I. Rappaport. 1972. Acquired inhibitors of blood coagulation in five patients. In Progress in Haemostasis and Thrombosis. Vol. 1. T. H. Spaet, editor. Grune and Stratton, Inc., New York. 75-79.

4. Harris, E. N., A. E. Gharavi, M. L. Bowie, B. M. Patel, C. G. MockworthYoung, S. Loizou, and G. R. V. Hughes. 1983. Anticardiolipin antibodies: detection by radioimmunoassay and association with thrombosis in systemic lupus erythematosus. Lancet ii:1211-1214.

5. Asherson, R. A., M. A. Khamashta, J. Ordi-Ros, R. H. W. M. Derksen, S. J. Machin, J. Barquinero, H. H. Outt, E. N. Harris, M. Vilardell, and G. R. V. Hughes. 1989. The "primary" antiphospholipid syndrome: major clinical and serological features. Medicine (Balt.). 68:366-374.

6. Harris, E. N., E. Baguley, R. A. Asherson, and G. R. V. Hughes. 1987. Clinical and serological features of the "antiphospholipid syndrome". Br. J. Rheumatol. 26:19. (Abstr.)

7. Hart, R. G., V. T. Miller, B. M. Coull, and V. Bril. 1984. Cerebral infarction associated with lupus anticoagulants: preliminary report. Stroke. 15:114-118.

8. Trimble, M., D. A. Bell, W. Brien, V. Hachinski, B. O'Keefe, C. McLay, and J. Black. 1990. The antiphospholipid syndrome: prevalence among patients with stroke and transient ischemic attacks. Am. J. Med. 88:593-597.

9. Reinertsen, J. L., J. H. Klippel, A. H. Johnson, A. D. Steinberg, J. L Decker, and D. L. Mann. 1978. B-Lymphocyte alloantigens associated with systemic lupus erythematosus. N. Engl. J. Med. 299:515-518.

10. Gibofsky, A., R. J. Winchester, M. Patarroyo, M. Fotino, and H. G. Kunkel. 1978. Disease associations of the Ia-like human alloantigens: contrasting patterns in rheumatoid arthritis and systemic lupus erythematosus. J. Exp. Med. 148:1728-1732.

11. Bell, D. A., and P. J. Maddison. 1980. Serologic subsets in systemic lupus erythematosus. An examination of autoantibodies in relationship to clinical features of disease and HLA antigens. Arthritis Rheum. 23:1268-1273.

12. Ahearn, J. M., T. T. Provost, C. A. Stevens, W. B. Bias, and F. C. Arnett. 1982. Interrelationships of HLA-DR, MB and MT phenotypes, autoantibody expression, and clinical features in systemic lupus erythematosus. Arthritis Rheum. 25:1031-1040.

13. Gammon, W. R., E. R. Heise, W. A. Burke, J. Fine, D. T. Woodley, and R. A. Briggaman. 1988. Increased frequency of HLA-DR2 in patients with autoantibodies to epidermolysis bullosa acquisita antigen: evidence that the expression of autoimmunity to type VII collagen is HLA class II associated. J. Invest. Dermatol. 91:228-232.

14. Gregerson, P. K. 1989. Biology of disease. HLA class II polymorphism: implications for genetic susceptibility to autoimmune disease. Lab. Invest. 61:519.

15. Hamilton, R. G., J. B. Harley, W. B. Bias, M. Roebber, M. Reichlin, M. C. Hochberg, and F. C. Arnett. 1988. Two Ro (SS-A) autoantibody responses in systemic lupus erythematosus. Correlation of HLA DR/DQ specificities with quantitative expression of Ro (SS-A) autoantibody. Arthritis Rheum. 31:496505 . 
16. Johnson, C. D., J. P. Edmonds, and E. J. Holborow. 1973. Precipitating antibody to DNA detected by two-stage electroimmunodiffusion. Lancet. ii:883886.

17. Aarden, L. A., E. R. deGroot, and T. E. W. Feltkamp. 1975. Immunology of DNA III. Crithidia luciliae, a simple substrate for the determination of antidsDNA with the immunofluorescence technique. Ann. NY Acad. Sci. 254:505515.

18. Blin, N., and D. W. Stafford. 1978. A general method for isolation of high molecular weight DNA from eukaroytes. Nucleic Acids Res. 3:2303-2308.

19. McDaniel, D. O., R. T. Acton, B. O. Barger, W. J. Koopman, and J. D. Reveille. 1987. Association of 9.2 kilobase PvuII class I major histocompatibility complex restriction fragment length polymorphism with ankylosing spondylitis. Arthritis Rheum. 30:894-900.

20. Long, E. O., C. T. Wake, J. Gorski, and B. Mach. 1983. Complete sequence of an HLA-DR $\beta$ chain genes. EMBO (Eur. Mol. Biol. Organ.) J. 2:389394.

21. Larhammar, D., J. J. Hyldig-Nielsen, B. Servenius, G. Anderson, L. Rask, and P. A. Peterson. 1983. Exon-intron organization and complete nucleotide sequence of a human major histocompatibility antigen DC $\beta$ gene. Proc. Natl. Acad. Sci. USA. 80:7313-7317.

22. Spielman, R. S., J. Lee, W. F. Bodmer, J. G. Bodmer, and J. Trowsdale. 1984. Six HLA-D region $\alpha$-chain genes on human chromosome 6: polymorphisms and associations of DQ $\alpha$-related sequences and DR types. Proc. Natl. Acad. Sci. USA. 81:3461-3465.

23. Feinberg, A. P., and B. Vogelstein. 1983. A technique for radiolabelling DNA restriction fragments to high specific activity. Anal. Biochem. 132:6-13.

24. Cohen, D., M. Simons, J. M. Lalouel, and B. DuPont. 1988. Nomenclature for HLA-RFLP. Tenth International Histocompatibility Workshop Newsletter. 2:44-51.

25. Reveille, J. D., R. R. Schrohenloher, R. T. Acton, and B. O. Barger. 1989. DNA analysis of HLA-DR and DQ genes in American blacks with systemic lupus erythematosus. Arthritis Rheum. 32:1243-1251.

26. Reveille, J. D., R. T. Acton, K. Anderson, B. O. Barger, and R. E. Schrohenloher. 1990. RFLP analysis of HLA-DR, DQ, DP and C4 alleles in Caucasians with systemic lupus erythematosus. J. Rheumatol. In press.

27. Kohonen-Corish, M. R. J., and S. W. Serjeantson. 1986. HLA-DR $\beta$ polymorphism revealed by Taq I correlate with HLA-DR specificities. Hum. Immunol. 15:263-271.

28. Carlsson, B., J. Wallin, J. Bohme, and E. Moller. 1987. HLA-DR-DQ haplotypes defined by restriction fragment analysis: correlation to serology. Hum. Immunol. 20:95-113.

29. MacMurray, A. J. J. I. Bell, D. Denney, D. Watling, L. S. Foster, and H. O. McDevitt. 1987. Molecular mapping of class II polymorphisms in the human major histocompatibility complex. II. DQ $\beta$. J. Immunol. 139:574-586.

30. Bell, J. I., D. Denney, A. MacMurray, L. Foster, D. Watling and H. O. McDevitt. 1987. Molecular mapping of class II polymorphisms in the human major histocompatibility complex. I. DR $\beta$. J. Immunol. 139:562-573.

31. Bidwell, J. L., E. A. Bidwell, D. A. Savage, D. Middleton, P. T. Klouda, and B. A. Bradley. 1988. A DNA-RFLP typing system that positively identifies serologically well defined and ill defined HLA-DR and DQ alleles, including DRw10. Transplantation. 45:640-646.

32. Gyllensten, U. B., and H. A. Erlich. 1988. Generation of single-stranded DNA by polymerase chain reaction and its application to direct sequencing of the HLA-DQ $\alpha$ locus. Proc. Natl. Acad. Sci. USA. 86:7652-7856.

33. Bodmer, J. G., S. G. E. Marsh, P. Parham, H. A. Erlich, E. Albert, W. F Bodmer, B. Dupont, B. Mach, W. R. Mayr, T. Sasazuki, G. M. Th. Schreuder, J. L. Strominger, A. Svejgaard, and P. I. Terasaki. 1990. Nomenclature for factors of the HLA system, 1989. Hum. Immunol. 28:326-342.

34. Tan, E. M., A. S. Cohen, F. F. Fries, A. T. Masi, D. J. McShane, N. F. Rothfield, J. G. Schaller, N. Talal, and R. J. Winchester. 1982. The 1982 revised criteria for the classification of systemic lupus erythematosus. Arthritis Rheum. 25:1271-1277.

35. Todd, J. A., H. Acha-Orbea, J. I. Bell, N. Chao, Z. Fronek, C. O. Jacob M. M. McDermott, A. A. Sinha, L. Timmerman, L. Steinman, and H. O. McDevitt. 1988. A molecular basis for MHC Class II-associated autoimmunity. Science (Wash. DC). 240:1003-1009.

36. Harley, J. B., M. Reichlin, F. C. Arnett, E. L. Alexander, W. B. Bias, and T. T. Provost. 1986. Gene interaction at HLA-DQ enhances autoantibody production in primary Sjogren's syndrome. Science (Wash. DC). 232:1145-1147.

37. Goldstein, R., M. Duvic, I. N. Targoff, M. Reichlin, A. M. McMenemy, J. D. Reveille, N. B. Warner, M. S. Pollack, and F. C. Arnett. 1990. HLA-D region genes associated with autoantibody responses to histidyl-transfer RNA synthetase (Jo-1) and other translation-related factors in myositis. Arthritis Rheum. 33:1240-1248.

38. Isern, R., F. C. Arnett, R. Goldstein, K. Anderson, E. Durban, D. Owerbach, and J. D. Reveille. 1990. Anti-centromere antibodies (ACA) are associated with HLA-DR $\beta 1$ third hypervariable sequences shared by HLA-DR 1 and DR4. Arthritis Rheum. 33:S32. (Abstr.)

39. Reveille, J. D., M. J. MacLeod, K. Whittington, and F. C. Arnett. 1990. The Ro/La autoantibody response is localized to the second hypervariable region of HLA-DQ $\alpha$ and DQ $\beta$ outermost domains. Arthritis Rheum. 33:S99. (Abstr.)

40. Olsen, M. L., F. C. Arnett, and J. D. Reveille. 1990. Anti-Sm and antiRNP antibodies are associated with distinct and different HLA-DQ $\alpha$ and $\beta$ chain genes. Arthritis Rheum. 33:S100. (Abstr.).

41. Khanduja, S., F. C. Arnett, and J. D. Reveille. 1990. HLA-DQ beta genes encode an epitope for lupus specific DNA antibodies. Clin. Res. In press.

42. Savi, M., G. F. Ferraccioli, T. M. Neri, P. Zanelli, P. P. Dall'Aglio, A. Tincani, G. Balestrieri, G. Carella, and R. Cattaneo. 1988. HLA-DR antigens and anticardiolipin antibodies in Northern Italian systemic lupus erythematosus patients. Arthritis Rheum. 31:1568-1570.

43. McHugh, N. J., and P. J. Maddison. 1989. HLA-DR antigens and anticardiolipin antibodies in patients with systemic lupus erythematosus. Arthritis Rheum. 32:1623-1624.

44. Brown, J. H., T. Jardetzky, M. Saper, B. Samraoui, P. Bjorkman, and D. C. Wiley. 1988. A hypothetical model of the foreign antigen binding site of class II histocompatibility molecules. Nature (Lond.). 332:6012-6015. 